BMJ Paediatrics Open

\title{
Sex differences in child and adolescent physical morbidity: cohort study
}

\author{
Helen Sweeting, ${ }^{1}$ Elise Whitley, ${ }^{1}$ Alison Teyhan, ${ }^{2}$ Kate Hunt ${ }^{1}$
}

To cite: Sweeting H, Whitley E, Teyhan A, et al. Sex differences in child and adolescent physical morbidity: cohort study. BMJ Paediatrics Open 2017;1:e000191. doi:10.1136/ bmjpo-2017-000191

- Additional material is published online only. To view, please visit the journal online (http://dx.doi.org/10.1136/ bmjpo-2017-000191).

Received 7 August 2017 Revised 23 November 2017 Accepted 27 November 2017

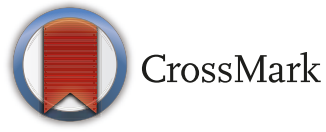

${ }^{1} \mathrm{MRC} / \mathrm{CSO}$ Social and Public Health Sciences Unit, University of Glasgow, Glasgow, UK ${ }^{2}$ Population Health Sciences, Bristol Medical School, University of Bristol, Bristol, UK

Correspondence to Dr Helen Sweeting; helen. sweeting@glasgow.ac.uk

\section{ABSTRACT}

Background Evidence on sex differences in physical morbidity in childhood and adolescence is based largely on studies employing single/few physical morbidity measures and different informants. We describe sex differences in a wide range of parent/carer-reported physical morbidity measures between ages 4 and 13 years to determine evidence for a generalised pattern of an emerging/ increasing female 'excess'.

Methods Parents/carers (approximately 90\% mothers) of the population-based UK ALSPAC cohort provided data on general health, physical conditions/symptoms and infections in their child approximately annually between ages 4 and 13. Logistic regression analyses determined the odds of each morbidity measure being reported in respect of females (vs males) at each age and the sex-byage interaction, to investigate any changing sex difference with age.

Results Six measures (general health past year/ month, high temperature, rash, eye and ear infections) demonstrated an emerging female 'excess', and six (earache, stomach-ache, headache, lice/scabies, cold sores, urinary infections) an increasing female 'excess'; one (breathlessness) showed a disappearing male 'excess'. Just two showed either an emerging or increasing male 'excess'. Most changes were evident during childhood (prepuberty). Six measures showed consistent female 'excesses' and four consistent male 'excesses'. Few measures showed no sex differences throughout this period of childhood/early adolescence.

Conclusion Sex differences are evident for a wide range of parent-reported physical morbidity measures in childhood and early adolescence. Far more measures showed an emerging/increasing female 'excess' than an emerging/increasing male 'excess'. Further studies are required to examine whether patterns differ across sociodemographic/cultural groups, and to explain this generalised pattern.

\section{INTRODUCTION}

An emerging or increasing female 'excess' in psychological morbidity ${ }^{1}{ }^{2}$ over the transition to adolescence is well recognised. Evidence of an emerging/increasing female 'excess' in several measures of common physical morbidity is less well established..$^{3-5}$ Furthermore, since most epidemiological studies focus on single, or small groups of conditions, the degree to which this might reflect a generalised pattern in sex differences

\section{What is already known on this topic?}

- Evidence of an emerging/increasing female 'excess' in physical morbidity over the transition to adolescence is less well established than that in respect of psychological morbidity.

- Most studies of sex differences in child/adolescent physical morbidity focus on single/few conditions, so cannot investigate the degree to which results reflect a generalised pattern.

\section{What this study adds?}

We observed a predominant pattern of an emerging/increasing female 'excess' in a broad range of physical morbidity measures between ages 4 and 13 years (rather than no sex differences or an emerging/increasing male 'excess').

- Further studies are required to corroborate and explain these findings and understand long-term implications for sex differences in adult health.

in physical morbidity has rarely been investigated.

A previous systematic review and meta-analysis, based on a range of self-reported/ routinely collected physical morbidity measures in Western children and adolescents, examined whether higher prevalence among males in childhood is replaced by higher prevalence among females in adolescence. $^{5}$ It found an emerging/increasing female 'excess' with increasing age for self-reported general health and several specific symptoms. This pattern was strongest for headache, abdominal pain and tiredness and weaker for back pain and dizziness. It was also evident for self-reported migraine, but not two conditions based on routinely collected data, epilepsy (no sex differences) and type 1 diabetes (weak emerging/increasing male 'excess'). The age when a female 'excess' was first evident varied by morbidity measure; around 6-8 years for self-assessed health, abdominal pain, dizziness and headache (earlier than expected given previous literature associating female puberty with these 
physical symptoms ${ }^{6-8}$ ), and around 9-11 years for back pain, sleeping problems/tiredness and migraine.

More robust evidence for an emerging/increasing female 'excess' in self-report than routinely collected data ${ }^{5}$ suggests the need for careful consideration of the impact of data source in studies/reviews focusing on morbidity measured over the transition to adolescence. Changing sex differences with age may reflect underlying biological changes, or societal expectations, of which conditions, symptoms or infections are more 'appropriate' for either males or females at different life stages. Apparent sex-by-age differences in morbidity may therefore partly reflect whether data are self-reported (impossible at younger ages), proxy-reported (requiring awareness of symptoms by another, with or without them having been specifically informed by the sufferer) or routinely collected (requiring awareness of symptoms by the sufferer or another, followed by presentation to, and diagnosis by, health professionals).

Further evidence from other reviews broadly suggests an emerging female 'excess' occurring around puberty in several measures of common physical morbidity, including asthma, ${ }^{9-12}$ eczema ${ }^{12}{ }^{13}$ and respiratory infections, ${ }^{14}$ a consistent female excess in both urinary tract infections ${ }^{1516}$ and musculoskeletal pain, ${ }^{17}$ and no clear sex-by-age pattern in food allergy. ${ }^{12}$ However, many such reviews do not consider the issue of data source, ${ }^{9} 10141517$ and while others refer to different methods/condition presentations, potential impacts on results are not considered systematically ${ }^{116}$ or at all. ${ }^{12}{ }^{13}$ Similarly, some studies of sex-by-age differences in common childhood/adolescent conditions are unclear about data source, ${ }^{18}$ or based on parental report at younger ages and self-report thereafter, but without acknowledging this might have impacted on results..$^{19} 20$

This paper presents analysis of sex differences in a wide range of parent/carer-reported (almost all mother-reported) physical morbidity measures (general health; conditions and symptoms; infections) between ages of 4 and 13 in a large UK birth cohort. This allows exploration of:

1. Whether there is evidence of an emerging/increasing female 'excess' across these measures, reflecting a generalised pattern;

2. When any emerging female 'excess' occurs;

3 . Whether the sex-by-age patterns seen in the more restricted set of child/adolescent self-reported physical morbidity measures and described in a previous systematic review ${ }^{5}$ are replicated in parent-reported measures.

\section{METHOD}

\section{Participants}

Data are from the Avon Longitudinal Study of Parents and Children (ALSPAC), ${ }^{21} 22$ a population-based cohort study in South-West England. Pregnant women with estimated delivery date 1 April 1991 to 31 December 1992, were invited to participate, resulting in a cohort of 14541 pregnancies, with 13988 singletons and first-born twins alive at 1 year.

ALSPAC's study website includes details of available data via a fully searchable data dictionary (www.bristol. ac.uk/alspac/researchers/access/). All data for this analysis were from 'child-based' questionnaires, completed by their main carer at roughly 1 year intervals, from approximately age 4 ( 57 months; $\mathrm{n}=4967$ male and 5252 female questionnaires; $90 \% \quad(\mathrm{n}=9234)$ completed by mothers) to 13 years ( 166 months; $\mathrm{n}=3682$ male and 3678 female questionnaires; 93\% ( $\mathrm{n}=6809$ ) completed by mothers).

\section{Measures}

Table 1 details the 32 morbidity measures analysed here and the child ages when they were included. Included measures comprised: three general health (health in past month and year, and health-related school absences); 19 conditions and symptoms (diarrhoea, vomiting, cough, high temperature, earache, ear discharge, stomach-ache, rash, wheezing, breathlessness, headache, constipation, lice/scabies, eczema, asthma, hay fever, pains in arms/legs, food/drink allergies, other allergies) and 10 infections (chicken pox, cold sores, eye infection, ear infection, chest infection, tonsillitis/laryngitis, influenza, cold, urinary infection, worm infections).

\section{Analyses}

For each morbidity measure, age-specific logistic regression analyses determined the odds of it being reported in respect of females (vs males). Sex-by-age interactions (testing for a changing sex difference with age) were then included in further logistic regression analyses, based on reports at all ages, with robust SEs to allow for non-independence of observations from the same child.

Results are presented as graphs for each measure, showing female versus male ORs at each age. The graphs have logarithmic scaling (eg, ORs of 2 (females twice as likely) and 0.5 (females half as likely) are the same distance from 1 (no sex difference)). The graphs are presented in three sections (general health; conditions and symptoms; infections) and, within these, according to potential patterns of sex-by-age differences, which a previous systematic review conceptualised in terms of four 'types,, 5 and are defined here as:

- 'Type 1': an emerging/increasing female 'excess', or disappearing male excess with age, occurring because female rates increase more than those of males or decrease less than those of males, resulting in a marked sex-by-age interaction. Type 1 patterns therefore include: (a) a male 'excess' reversing to a female 'excess', or no sex difference at younger ages, but a female 'excess' at older ages (emerging female 'excess'); (b) a female 'excess' at younger ages, increasing with age (increasing female 'excess') or (c) a male 'excess' at younger ages, but no sex difference at older ages (disappearing male 'excess'). For 'type 1' patterns, the odds of morbidity among females com- 
Table 1 Morbidity measures and ages collected

\begin{tabular}{|c|c|c|c|c|c|c|c|c|c|c|c|}
\hline \multirow[b]{2}{*}{ Measure } & \multirow{2}{*}{$\begin{array}{l}\text { How coded for analysis/ } \\
\text { additional notes }\end{array}$} & \multicolumn{10}{|c|}{ Age in months } \\
\hline & & 57 & 65 & 69 & 81 & 91 & 103 & 128 & 140 & 157 & 166 \\
\hline \multicolumn{12}{|l|}{ General health } \\
\hline $\begin{array}{l}\text { How would you } \\
\text { assess the health of } \\
\text { your child in the past } \\
\text { month? In the past } \\
\text { year? }\end{array}$ & $\begin{array}{l}\text { 'Sometimes quite ill' or 'almost } \\
\text { always unwell' (categorised } \\
\text { here together as 'poor') vs 'very } \\
\text { healthy, no problems' or 'healthy, } \\
\text { but a few minor problems' }\end{array}$ & $x$ & & $\mathrm{X}$ & $\mathrm{X}$ & $x$ & $x$ & $x$ & $x$ & $x$ & $x$ \\
\hline $\begin{array}{l}\text { How many days the } \\
\text { child had taken off } \\
\text { school in the past } \\
\text { year. }\end{array}$ & $\begin{array}{l}\text { For a range of health reasons } \\
\text { (infections, asthma/eczema/ } \\
\text { hay fever, hospital or other } \\
\text { investigations/admissions, other } \\
\text { reasons). Any days off for any } \\
\text { health reason vs none }\end{array}$ & & & & & $x$ & $x$ & $x$ & $x$ & & $x$ \\
\hline \multicolumn{12}{|c|}{ Conditions and symptoms } \\
\hline $\begin{array}{l}\text { Has child had any of } \\
\text { the following? }\end{array}$ & $\begin{array}{l}\text { Since age } 3 \text { (at } 57 \text { months); in the } \\
\text { past } 15 \text { months (at } 69 \text { months); in } \\
\text { the past year (all other ages) }\end{array}$ & & & & & & & & & & \\
\hline Diarrhoea & & $x$ & & $X$ & $\mathrm{X}$ & $X$ & $x$ & $\mathrm{X}$ & & $x$ & $x$ \\
\hline Vomiting & & $x$ & & $\mathrm{X}$ & $x$ & $x$ & $x$ & $x$ & & $x$ & $x$ \\
\hline Cough & & $x$ & & $\mathrm{X}$ & $\mathrm{X}$ & $\mathrm{X}$ & $x$ & $x$ & & $x$ & $x$ \\
\hline High temperature & & $x$ & & $x$ & $x$ & $x$ & $x$ & $x$ & & $x$ & $x$ \\
\hline Earache & & $x$ & & $\mathrm{X}$ & $x$ & $x$ & $x$ & $x$ & & $x$ & $x$ \\
\hline Ear discharge (pus) & & $x$ & & $x$ & $x$ & $x$ & $x$ & $x$ & & $x$ & $x$ \\
\hline Stomach-ache(s) & & $x$ & & $x$ & $\mathrm{X}$ & $x$ & $x$ & $x$ & & $x$ & $x$ \\
\hline Rash & & $x$ & & $\mathrm{X}$ & $x$ & $x$ & $x$ & $x$ & & $x$ & $x$ \\
\hline Wheezing & & $x$ & & $\mathrm{X}$ & $\mathrm{X}$ & $x$ & $x$ & $x$ & & $x$ & $x$ \\
\hline Breathlessness & & $x$ & & $\mathrm{X}$ & $x$ & $x$ & $x$ & $x$ & & $x$ & $x$ \\
\hline Headache(s) & & $x$ & & $\mathrm{X}$ & $\mathrm{X}$ & $x$ & $x$ & $x$ & & $x$ & $x$ \\
\hline Constipation & & $x$ & & $\mathrm{X}$ & $x$ & $x$ & $x$ & $x$ & & $x$ & $x$ \\
\hline Lice or scabies & $\begin{array}{l}\text { Asked separately from } 81 \text { months; } \\
\text { combined for consistency in } \\
\text { analyses }\end{array}$ & $X$ & & $x$ & $\mathrm{x}$ & $x$ & $x$ & $x$ & & $x$ & $x$ \\
\hline
\end{tabular}

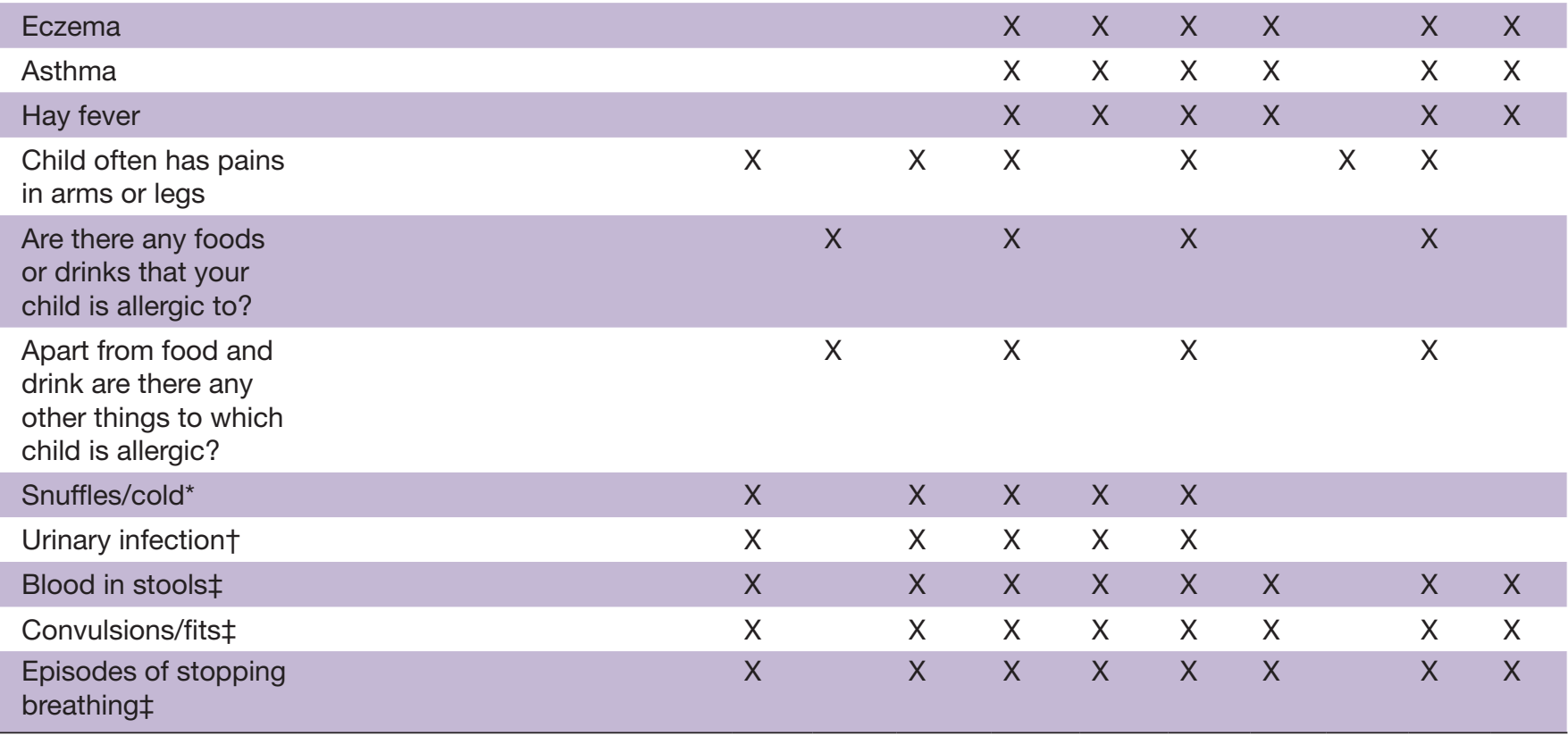


Table 1 Continued

\begin{tabular}{|c|c|c|c|c|c|c|c|c|c|c|c|}
\hline \multirow[b]{2}{*}{ Measure } & \multirow{2}{*}{$\begin{array}{l}\text { How coded for analysis/ } \\
\text { additional notes }\end{array}$} & \multicolumn{10}{|c|}{ Age in months } \\
\hline & & 57 & 65 & 69 & 81 & 91 & 103 & 128 & 140 & 157 & 166 \\
\hline $\begin{array}{l}\text { Convulsion, fit } \\
\text { or seizure due to } \\
\text { epilepsy } \ddagger\end{array}$ & & $x$ & & $x$ & $\mathrm{x}$ & & $x$ & & $x$ & & \\
\hline Accident§ & & $x$ & & $x$ & $x$ & $x$ & $x$ & $x$ & & $x$ & $x$ \\
\hline \multicolumn{12}{|l|}{ Infections } \\
\hline $\begin{array}{l}\text { Has child had any } \\
\text { of the following } \\
\text { infections? }\end{array}$ & $\begin{array}{l}\text { Since age } 3 \text { (at } 57 \text { months); in the } \\
\text { past } 15 \text { months (at } 69 \text { months); in } \\
\text { the past year (all other ages) }\end{array}$ & & & & & & & & & & \\
\hline Chicken pox & & $x$ & & $x$ & $x$ & $x$ & $x$ & $x$ & & & $x$ \\
\hline Cold sores & & $x$ & & $x$ & $x$ & $x$ & $x$ & $x$ & & & $x$ \\
\hline Eye infection & & $x$ & & $x$ & $x$ & $x$ & $x$ & $x$ & & & $x$ \\
\hline Ear infection & & $x$ & & $x$ & $x$ & $x$ & $x$ & $x$ & & & $x$ \\
\hline Chest infection & & $x$ & & $x$ & $x$ & $x$ & $x$ & $x$ & & & $x$ \\
\hline Tonsilitis/laryngitis & & & & & & $x$ & $x$ & $x$ & & & $x$ \\
\hline Influenza & & & & & & $x$ & $x$ & $\mathrm{x}$ & & & $\mathrm{x}$ \\
\hline Cold ${ }^{*}$ & & & & & & $x$ & $x$ & $x$ & & & $x$ \\
\hline Urinary infection† & & $x$ & & $x$ & $\mathrm{X}$ & $x$ & $x$ & $x$ & & & $x$ \\
\hline Worm infections & & $x$ & & $x$ & $\mathrm{x}$ & $\mathrm{x}$ & $\mathrm{x}$ & $x$ & & $x$ & $\mathrm{x}$ \\
\hline Measlesł & & $x$ & & $x$ & $x$ & $x$ & $x$ & $x$ & & & $x$ \\
\hline Mumpsł & & $x$ & & $x$ & $x$ & $x$ & $x$ & $x$ & & & $x$ \\
\hline Meningitisł & & $x$ & & $x$ & $x$ & $x$ & $x$ & $x$ & & & $x$ \\
\hline Whooping cough $\ddagger$ & & $x$ & & $x$ & $\mathrm{X}$ & $x$ & $x$ & $x$ & & & $x$ \\
\hline German measlesł & & & & & & $x$ & $x$ & $x$ & & & $x$ \\
\hline Scarlet fever $\ddagger$ & & & & & & $x$ & $\mathrm{x}$ & $x$ & & & $x$ \\
\hline Glandular fever** & & & & & & & & & & & $x$ \\
\hline
\end{tabular}

*Reported by parent as 'cold/snuffles' (within conditions list) at 57, 69, 81, 91 and 103 months and 'cold' (within infections list) at 128,157 and 166 months were combined and included here as 'cold' (categorised under infections).

†Reported by parent within both conditions (57-103 months) and infections (57-166 months) lists, so only results in respect of infections data included here.

‡Excluded from analyses as reported in respect of very small numbers (fewer than 20 males and/or females).

$\S$ Excluded from analyses as out with the scope of the paper.

IReported by parent within conditions list, but included here within infections.

${ }^{\star *}$ Excluded from analysis as only one time point.

pared with males start below, at, or above unity and increase with age.

- 'Type 2': (a) stable female 'excess'; (b) stable lack of a sex difference or (c) stable male 'excess'. For 'type 2' patterns, the odds of female versus male morbidity are consistently either above, below or at unity.

- 'Type 3': variations on an emerging/increasing male 'excess', or disappearing female 'excess' (the reverse of 'type 1'). For 'type 3' patterns, the odds of female versus male morbidity start above, at or below unity and decrease with age.

- 'Type 4': mixed/unclassifiable patterns.

(Note precise definitions are included as footnotes to the results graphs.)

Results are based on cross-sectional samples at each age. Two sets of sensitivity analyses were completed. One was restricted to a longitudinal subsample, selecting only those for whom data were available at all relevant ages, $n=4454$. The other was conducted for the 'mother-only' subsample, selecting only mother-completed data, to investigate whether completion by different carers at different ages might impact on the results. Online supplementary table 1 shows cross-sectional, longitudinal and mother-only sample sizes. Online supplementary table 2 shows the characteristics of those included/not included in the samples and demonstrates that due to sample attrition, those included were more likely to be first-born children of mothers in a first marriage, of higher socioeconomic status, and who had never smoked. Results from both the longitudinal and mother-only samples were almost identical to the cross-sectional results. Online supplementary tables 
Type 1a: Emerging female excess ${ }^{1 a}$

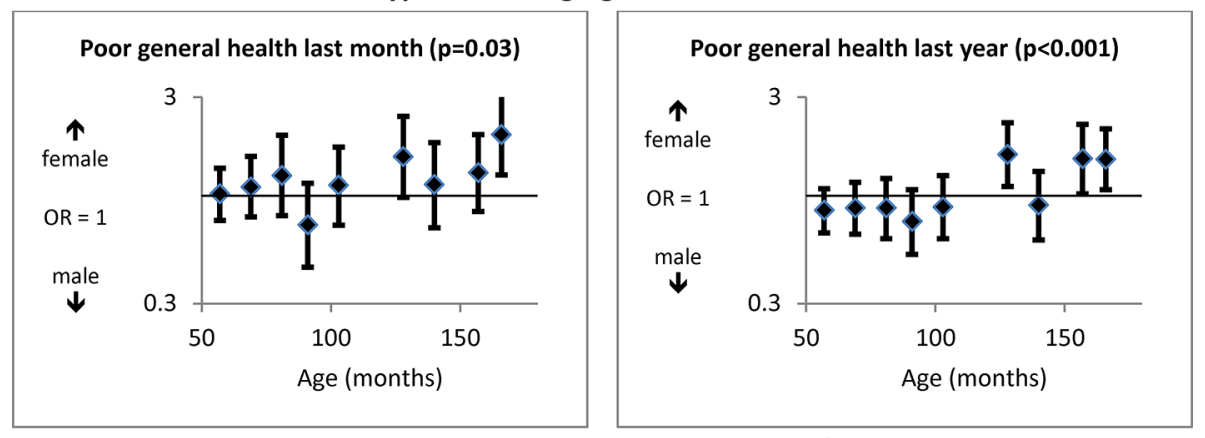

Type 2a: Consistent female excess ${ }^{2 a}$

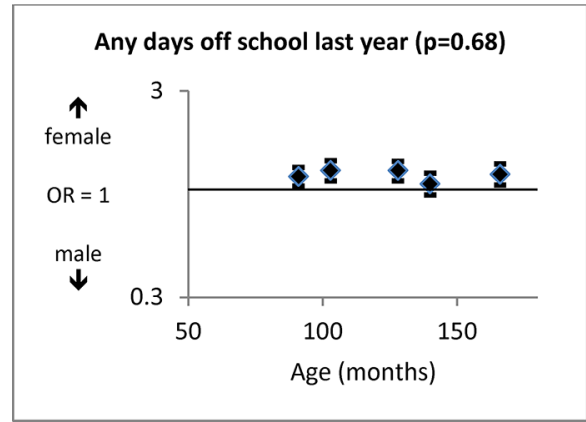

${ }^{1 a}$ Emerging female excess defined as: odds ratios (ORs) at youngest age(s) show a marked male excess or no sex difference; ORs at oldest age(s) show a marked female excess; sex-by-age interaction is marked.

${ }^{2 a}$ Consistent female excess defined as: majority of ORs show a marked female excess; sex-by-age interaction is not marked.

Figure 1 General health measures (with $\mathrm{P}$ values for significance of sex-by-age interactions).

3-5 show results based on each sample. Finally, given that some have suggested Poisson as an alternative to logistic regression for analysis of cross-sectional studies with binary outcomes, ${ }^{23}$ we also conducted Poisson regression analyses on the cross-sectional samples. Results (expressed as risk ratios, rather than ORs) were very similar to those obtained via logistic regression (see online supplementary tables 6-8).

\section{RESULTS}

\section{General health}

Figure 1 shows a 'type 1a' female 'excess' emerging by 128 months for parent-reported poor general health in their child over the last month $(\mathrm{OR}=1.02,95 \%$ CI 0.76 to 1.36 at 57 months; $\mathrm{OR}=1.97,95 \%$ CI 1.26 to 3.10 at 166 months; sex-by-age interaction $\mathrm{P}=0.01)$ and the last year $(\mathrm{OR}=0.85,95 \%$ CI 0.66 to 1.08 at 57 months; $\mathrm{OR}=1.50,95 \%$ CI 1.07 to 2.11 at 166 months; interaction $\mathrm{P}<0.001)$. Days off school in the last year was unavailable at the youngest ages, but showed a small consistent female 'excess' ('type 2a' pattern) from 91 to 166 months $(\mathrm{OR}=1.15,95 \%$ CI 1.04 to 1.28 at 91 months; $\mathrm{OR}=1.18$, $95 \%$ CI 1.05 to 1.33 at 166 months; interaction $\mathrm{P}=0.68$ ).

\section{Conditions and symptoms}

Figure 2 shows that for 6 of the 20 conditions/symptoms measures, there was an emerging/increasing female 'excess', while one showed a disappearing male 'excess' (all 'type 1' patterns). Thus, although there were no sex differences at younger ages, a female 'excess' emerged in respect of rates of parent-reported high temperature by 128 months and, more markedly, rash by 81 months (interaction $\mathrm{P}=0.01$ and $<0.001$, respectively). Earache, stomach-ache, headache and head lice/scabies were more likely to be reported in respect of females at younger ages, but this female 'excess' increased with age (interaction $\mathrm{P}<0.001)$. Reported breathlessness also showed a type 1 sex-by-age interaction, from a male 'excess' at younger ages which disappeared, resulting in no sex difference at older ages $(\mathrm{OR}=0.63,95 \% \mathrm{CI} 0.54$ to 0.73 at 57 months; $\mathrm{OR}=1.05,95 \%$ CI 0.87 to 1.26 at 166 months; interaction $\mathrm{P}<0.001)$.

Ten conditions/symptoms showed stable ('type 2') sex differences/lack of sex differences with age. Thus, two (constipation and eczema) showed a female 'excess' at almost all ages and three a consistent male 'excess' (wheezing, asthma and hay fever). A further five were largely consistent in showing no marked sex difference at any age (cough, vomiting, ear discharge, food and other allergy).

Finally, two conditions/symptoms (pain in arms/legs and diarrhoea) showed an emerging/increasing male 'excess' ('type 3' patterns). There was no sex difference in respect of pain in arms/legs at younger ages $(\mathrm{OR}=0.95$, 95\% CI 0.85 to 1.07 at 57 months), but a small male 'excess' emerged by 140 months and was maintained at 157 months $(\mathrm{OR}=0.81,95 \%$ CI 0.74 to 0.90 at 157 months; interaction $\mathrm{P}=0.001)$. Diarrhoea showed an increasing 


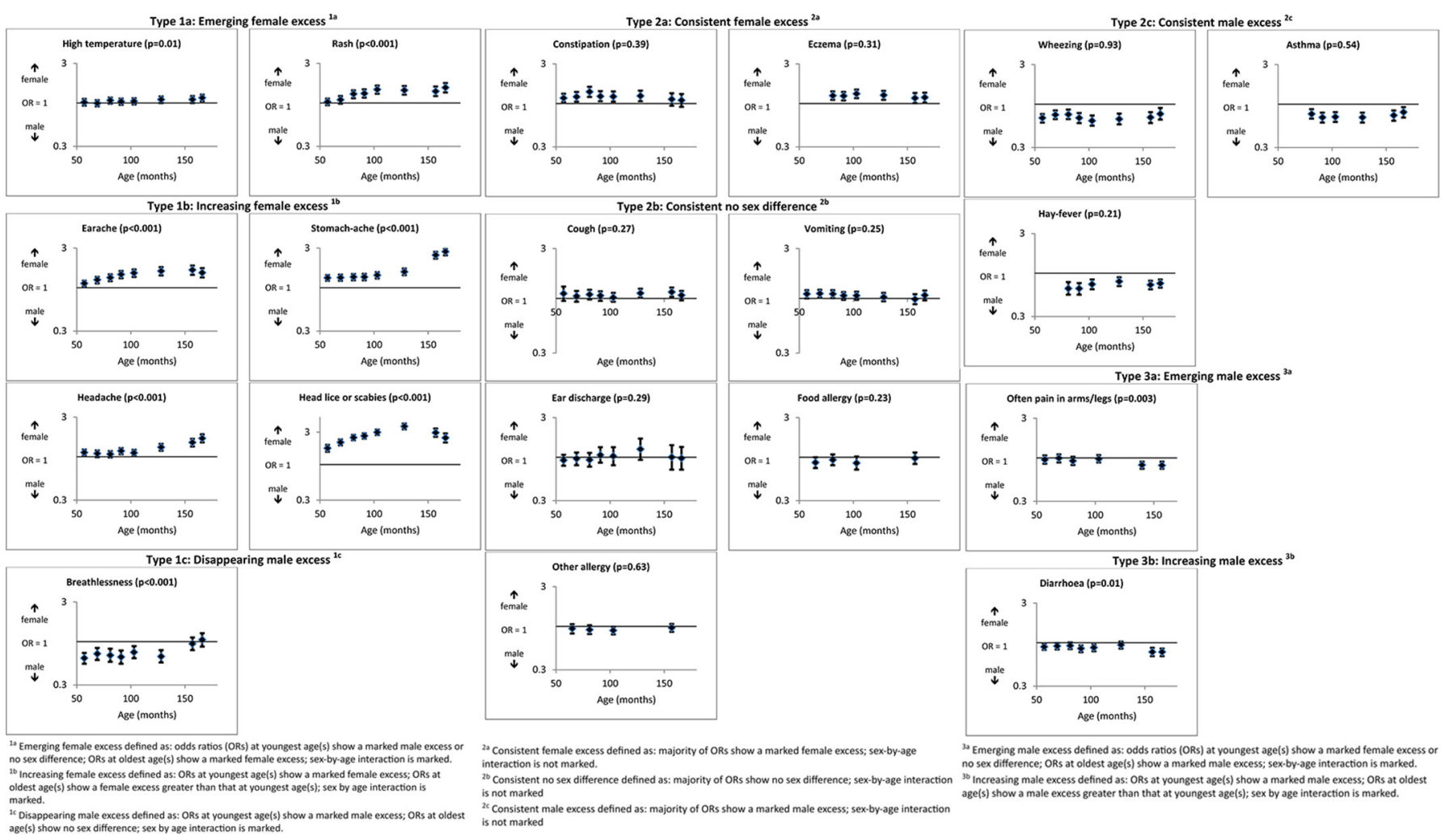

Figure 2 Conditions/symptoms measures (with $\mathrm{P}$ values for significance of sex-by-age interactions).

male 'excess', being more likely to be reported in males at all ages, particularly older ages $(\mathrm{OR}=0.89,95 \%$ CI 0.82 to 0.96 at 57 months; $\mathrm{OR}=0.77,95 \%$ CI 0.69 to 0.85 at 166 months; interaction $\mathrm{P}=0.004)$.

\section{Infections}

Figure 3 shows an emerging/increasing female 'excess' in 4 of the 11 parent-reported infections ('type 1' patterns), a consistent female 'excess' in 3, a consistent male 'excess' in 1 and no sex difference in 2 ('type 2' patterns).

Among infections showing an emerging/increasing female 'excess', there were no sex differences in parent-reported child eye and ear infections at younger ages, but a female 'excess' emerged for eye infections by 103 months and ear infections by 81 months (interaction $\mathrm{P}<0.001$ for both). Parent-reported cold sores and, more markedly, urinary infections (note different scale on graph) were higher in females0 at all ages, but this sex difference increased with age (eg, for urinary infections, $\mathrm{OR}=2.35$, 95\% CI 1.97 to 2.81 at 57 months; OR=5.13, 95\% CI 3.30 to 7.98 at 166 months; interaction $\mathrm{P}<0.001)$. Finally, among the infections showing 'type 2' patterns, there was a consistent female 'excess' in respect of reported tonsillitis, cold/ snuffles and worm infections, no sex difference in chicken pox and influenza and a consistent male 'excess' in respect of chest infections.

\section{DISCUSSION}

This is the first study to examine sex differences in a range of parent-reported physical morbidity measures during childhood and adolescence and explore age-based changes. (Table 2)

Given evidence of a generalised pattern for psychological morbidity measures, we were interested in whether there was also a generalised pattern of an emerging/ increasing female 'excess' across these physical morbidity measures and, if so, when this occurred. As summarised in table 2, of the 32 measures examined, only 7 showed no sex differences throughout the included age ranges. Six were categorised as showing an emerging female 'excess', six an increasing female 'excess' one a disappearing male 'excess' ('type 1' patterns) and six a consistent female 'excess'. In contrast, only one showed an emerging male 'excess', one an increasing male 'excess' ('type 3' patterns) and four a consistent male 'excess'. Thus, far more measures showed an emerging/increasing female 'excess' than an emerging/ increasing male 'excess' or no sex difference.

We also wished to know whether sex-by-age patterns in a more restricted set of child/adolescent self-reported physical morbidity measures described in a previous review, ${ }^{5}$ were replicated when these measures were parent-reported, as here. Three measures (general health, headache, abdominal pain) are included in both studies. The review found a marked female 'excess' in each, based on self-reports, from around $6-8$ years. The current analysis, based on parent-reported measures, had broadly similar findings, but suggested an even earlier small female 'excess' in headache and stomach-ache.

How can these complex patterns of sex differences in parent-reported morbidity be explained? Female 

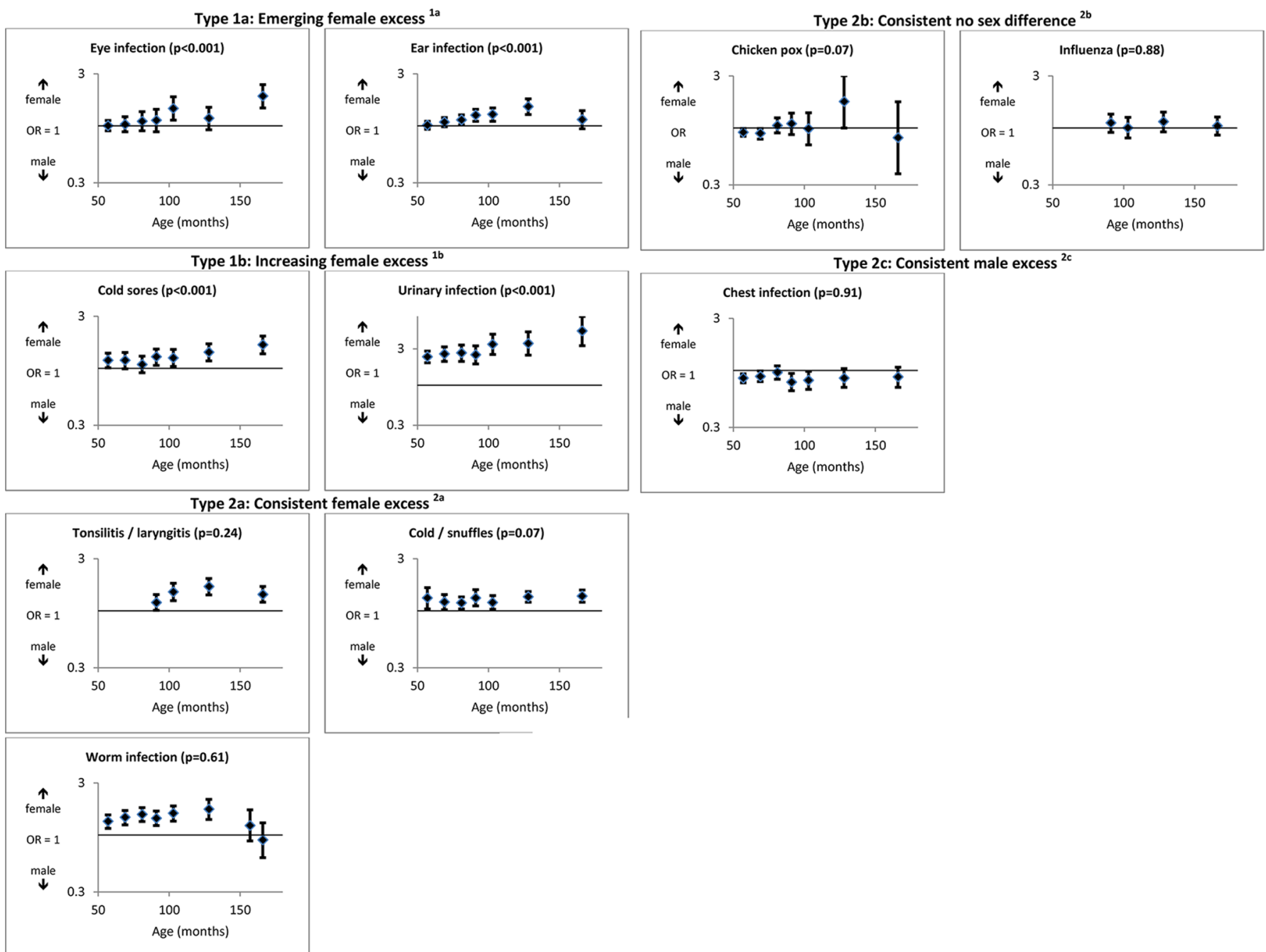

${ }^{1 a}$ Emerging female excess defined as: odds ratios (ORs) at youngest age(s) show a marked male excess or no sex difference; ORs at oldest age(s) show a marked female excess; sex-by-age interaction is marked. ${ }^{1 b}$ Increasing female excess defined as: ORs at youngest age(s) show a marked female excess; ORs at oldest age(s) show a female excess greater than that at youngest age(s); sex by age interaction is marked.

${ }^{2 a}$ Consistent female excess defined as: majority of ORs show a marked female excess; sex-by-age interaction is not marked.

${ }^{2 b}$ Consistent no sex difference defined as: majority of ORs show no sex difference; sex-by-age interaction is not marked

${ }^{2 c}$ Consistent male excess defined as: majority of ORs show a marked male excess; sex-by-age interaction is not marked

Figure 3 Infections measures (with $\mathrm{P}$ values for significance of sex-by-age interactions).

puberty is associated with physical symptoms, including menstrual cramps and headaches. ${ }^{6-8}$ Although previous literature suggests higher male rates of asthma, eczema, respiratory infections and perhaps hay fever at younger ages, reversing around puberty, ${ }^{9-14} 1819$ we observed a consistent male 'excess' in asthma, wheeze, hay fever and chest infections throughout the age range considered here. It is possible that a 'reversal' occurred later in puberty in the ALSPAC cohort. However, the consistently higher female eczema rates cannot be explained in this way. While potential explanations might be constructed for some findings (eg, the increasing female 'excess' in lice/scabies throughout childhood might result from girls' often longer hair and/or greater time spent in physically close social interactions ${ }^{24}$ ), others, such as an emerging/increasing female 'excesses' in temperature, rash, earache/infection, eye infection or cold sores are harder to explain.
Another potential explanation is that some of these sex differences in parent-reported morbidity measures result from different illness-related attitudes/expectations (by both children and parents) in respect of males compared with females. Parental expectations about, and reinforcement of, their child's emotional expressivity differ according to child sex, ${ }^{25}$ as do ratings of, and responses to, paediatric pain. ${ }^{2627}$ Perhaps these translate into differences in acknowledging, recalling and reporting illness in respect of boys and girls. There are few studies in this area and stereotyped attitudes and expectations relating to sex differences may differ according to what aspect of child morbidity is being considered.

The strengths of this study include its large sample size and wide range of morbidity measures, enabling us to address previously unexplored questions. Analyses based on cross-sectional samples produced almost identical results to those limited to the longitudinal sample (which 
Table 2 Summary of patterns of sex-by-age differences in each morbidity measure

\section{General health Conditions and symptoms Infections}

\begin{tabular}{|c|c|c|c|}
\hline \multicolumn{4}{|l|}{ 'Type 1' } \\
\hline 1a: Emerging female excess & $\begin{array}{l}\text { General health - Past year } \\
\text { General health - Past month }\end{array}$ & $\begin{array}{l}\text { High temperature } \\
\text { Rash }\end{array}$ & $\begin{array}{l}\text { Eye infection } \\
\text { Ear infection }\end{array}$ \\
\hline $1 \mathrm{~b}$ : Increasing female excess & & $\begin{array}{l}\text { Earache } \\
\text { Stomach-ache } \\
\text { Headache } \\
\text { Lice/scabies }\end{array}$ & $\begin{array}{l}\text { Cold sores } \\
\text { Urinary infection }\end{array}$ \\
\hline
\end{tabular}

1c: Disappearing male excess

Breathlessness

'Type 2'

2a: Consistent female excess

Health-related days off school

Constipation

Eczema

Tonsillitis/laryngitis

Cold

Worm infections

2b: Consistent no sex difference

Vomiting

Cough

Chicken pox

Ear discharge

Influenza

Food/drink allergies

Non-food/drink allergies

2c: Consistent male excess

Wheezing

Chest infection

Asthma

Hay fever

'Type 3'

3a: Emerging male excess

Pain in arms/legs

$3 \mathrm{~b}$ : Increasing male excess

Diarrhoea

was subject to differential attrition) and mother-only samples (which eliminated different carers reporting on a child's health at different ages). Findings such as the much higher rates of urinary infections among females at all ages and markedly increasing female 'excess' in stomach and headaches in early adolescence, are consistent with other research. ${ }^{6-81516}$ However, we also draw attention to potential limitations. Our categorisation of patterns of sex-by-age differences in physical morbidity, based on graphs and interactions, could be regarded as simple, and the fact that we conducted analyses on 32 morbidity measures introduces the possibility of spurious (chance) significance for some sex-by-age interactions due to multiple testing. However, our focus was on consistent patterns of ORs with age and these are unlikely to have arisen purely by chance. In addition, there is no reason to think that spurious interactions would occur more often for measures showing a 'type 1' pattern. Another limitation is that this secondary analysis of existing data from a well-established cohort was inevitably limited by the specific measures chosen by the ALSPAC team at each age. In particular, lack of comparable data at older ages prevents extension of the analysis to mid-later adolescence. Furthermore, although there was little evidence of differential attrition according to child sex, the sample was more advantaged than the general population, thus potentially limiting generalisability of the findings.

Based on rigorous analysis questioning, we believe for the first time, whether age-based changes in sex differences in child and adolescent physical morbidity follow specific patterns (as proposed in a prior review ${ }^{5}$ ), this analysis suggests both substantive and methodological conclusions. Substantively, it is intriguing that sex differences are evident in respect of a wide range of parent-reported physical morbidity measures in childhood and early adolescence, generally indicating poorer health in girls. While some measures show consistent female or male 'excesses', many show an emerging/ increasing female 'excess' in childhood, consistent with findings for psychological morbidity, ${ }^{12}$ which are evident prepuberty; almost none shows an emerging/increasing male 'excess'. This pattern of 'excess' female morbidity by/before puberty highlights important inequities, with public health implications, not least in future health service usage. Many of these (changing) sex differences are hard to explain on the basis of existing literature, suggesting, as in adults, ${ }^{28}$ the need for further quantitative studies to corroborate these findings and to examine whether patterns differ across sociodemographic or cultural groups. There is also a need for further qualitative or experimental studies to examine the social and/ or biological mechanisms underlying these findings. ${ }^{29} 30$ Methodologically, possible differences according to data source (routine data, child/proxy-reported) highlight the need for reviews of sex-by-age differences in child/ adolescent morbidity to pay close attention to this issue and for studies which systematically compare results based on multiple sources. 
Acknowledgements The authors are extremely grateful to all the families who took part in this study, the midwives for their help in recruiting them and the whole ALSPAC team, which includes interviewers, computer and laboratory technicians, clerical workers, research scientists, volunteers, managers, receptionists and nurses.

Contributors HS conceptualised and designed the study with $\mathrm{KH}$, lead the data request and drafted all versions of the manuscript. EW advised on the data request, carried out the analyses, produced the graphical results and commented on all versions of the manuscript. AT advised on the data request, conducted the data extraction and commented on later versions of the manuscript. KH conceptualised and designed the study with HS and commented on all versions of the manuscript. All authors approved the final manuscript as submitted.

Funding This work was supported by the UK Medical Research Council, Wellcome Trust and University of Bristol. The UK Medical Research Council and Wellcome (Grant ref: 102215/2/13/2) and the University of Bristol provide core support for ALSPAC. HS, EW and KH are funded by the UK Medical Research Council MC_UU_12017/12 and MC_UU_12017/13. AT is supported by PEARL (Project to Enhance ALSPAC through Record Linkage), a programme of research funded by the Wellcome Trust (WT086118/Z/08/Z).

Competing interests None declared.

Ethics approval Ethical approval was obtained from the ALSPAC Law and Ethics Committee and local research ethics committee.

Provenance and peer review Not commissioned; externally peer reviewed.

Data sharing statement ALSPAC's study website includes details of available data via a fully searchable data dictionary (www.bristol.ac.uk/alspac/researchers/ access/). Our analysis was based on variables which we specifically requested.

Open Access This is an Open Access article distributed in accordance with the terms of the Creative Commons Attribution (CC BY 4.0) license, which permits others to distribute, remix, adapt and build upon this work, for commercial use, provided the original work is properly cited. See: http://creativecommons.org/ licenses/by/4.0/

C) Article author(s) (or their employer(s) unless otherwise stated in the text of the article) 2017. All rights reserved. No commercial use is permitted unless otherwise expressly granted.

\section{REFERENCES}

1. Cyranowski JM, Frank E, Young E, et al. Adolescent onset of the gender difference in lifetime rates of major depression: a theoretical model. Arch Gen Psychiatry 2000;57:21-7.

2. Nolen-Hoeksema S, Girgus JS. The emergence of gender differences in depression during adolescence. Psychol Bull 1994;115:424-43.

3. Sweeting $\mathrm{H}$. Reversals of fortune? Sex differences in health in childhood and adolescence. Soc Sci Med 1995;40:77-90.

4. Torsheim T, Ravens-Sieberer U, Hetland J, et al. Cross-national variation of gender differences in adolescent subjective health in Europe and North America. Soc Sci Med 2006;62:815-27.

5. MacLean A, Sweeting $H$, Egan $M$, et al. How robust is the evidence of an emerging or increasing female excess in physical morbidity between childhood and adolescence? Results of a systematic literature review and meta-analyses. Soc Sci Med 2013;78:96-112.

6. Beal SJ, Dorn LD, Sucharew HJ, et al. Characterizing the longitudinal relations between depressive and menstrual symptoms in adolescent girls. Psychosom Med 2014;76:547-54.
7. Harel Z. Dysmenorrhea in adolescents. Ann N Y Acad Sci 2008;1135:185-95.

8. LeResche L, Mancl LA, Drangsholt MT, et al. Relationship of pain and symptoms to pubertal development in adolescents. Pain 2005;118:201-9.

9. Zannolli R, Morgese G. Does puberty interfere with asthma? Med Hypotheses 1997;48:27-32.

10. Postma DS. Gender differences in asthma development and progression. Gend Med 2007;4(Suppl B):S133-S146.

11. Almqvist $\mathrm{C}$, Worm $\mathrm{M}$, Leynaert $\mathrm{B}$. Impact of gender on asthma in childhood and adolescence: a GA2LEN review. Allergy 2008;63:47-57.

12. Chen W, Mempel M, Schober W, et al. Gender difference, sex hormones, and immediate type hypersensitivity reactions. Allergy 2008;63:1418-27.

13. Modjtahedi BS, Modjtahedi SP, Maibach HI. The sex of the individual as a factor in allergic contact dermatitis. Contact Dermatitis 2004;50:53-9.

14. Heikkinen T, Järvinen A. The common cold. Lancet 2003;361:51-9.

15. Chang SL, Shortliffe LD. Pediatric urinary tract infections. Pediatr Clin North Am 2006;53:379-400.

16. Foxman B. Epidemiology of urinary tract infections: incidence, morbidity, and economic costs. Am J Med 2002;113:5S-13.

17. King S, Chambers CT, Huguet A, et al. The epidemiology of chronic pain in children and adolescents revisited: a systematic review. Pain 2011:152:2729-38.

18. Yao TC, Ou LS, Yeh KW, et al. Associations of age, gender, and BMI with prevalence of allergic diseases in children: PATCH study. $J$ Asthma 2011;48:503-10.

19. Kurukulaaratchy RJ, Karmaus W, Raza A, et al. The influence of gender and atopy on the natural history of rhinitis in the first 18 years of life. Clin Exp Allergy 2011;41:851-9.

20. Roth-Isigkeit $A$, Thyen $U$, Stöven $\mathrm{H}$, et al. Pain among children and adolescents: restrictions in daily living and triggering factors. Pediatrics 2005;115:e152-e162.

21. Boyd A, Golding J, Macleod J, et al. Cohort Profile: the 'children of the 90s'--the index offspring of the Avon Longitudinal Study of Parents and Children. Int J Epidemiol 2013;42:111-27.

22. Golding J, Pembrey M, Jones R, et al. ALSPAC--the Avon Longitudinal Study of Parents and Children. I. Study methodology. Paediatr Perinat Epidemiol 2001;15:74-87.

23. Barros AJ, Hirakata VN. Alternatives for logistic regression in crosssectional studies: an empirical comparison of models that directly estimate the prevalence ratio. BMC Med Res Methodol 2003;3:21.

24. Rose AJ, Rudolph KD. A review of sex differences in peer relationship processes: potential trade-offs for the emotional and behavioral development of girls and boys. Psychol Bull 2006;132:98-131.

25. Eisenberg N, Cumberland A, Spinrad TL. Parental socialization of emotion. Psychol Inq 1998:9:241-73.

26. Cohen LL, Cobb J, Martin SR. Gender biases in adult ratings of pediatric pain. Children's Health Care 2014;43:87-95.

27. Langer SL, Walker LS, Romano JM, et al. Predictors of maternal responses to child abdominal pain. Children's Health Care 2007;36:63-81.

28. Macintyre S, Hunt K, Sweeting H. Gender differences in health: are things really as simple as they seem? Soc Sci Med 1996;42:617-24.

29. Maclean A, Sweeting H, Hunt K. 'Rules' for boys, 'guidelines' for girls: Gender differences in symptom reporting during childhood and adolescence. Soc Sci Med 2010;70:597-604.

30. Sweeting HN, West PB, Der GJ. Explanations for female excess psychosomatic symptoms in adolescence: evidence from a school-based cohort in the West of Scotland. BMC Public Health 2007;7:298. 